\title{
EL MITO DE HERO Y LEANDRO: ALGUNAS FUENTES GRECOLATINAS Y SU PERVIVENCIA EN EL SIGLO DE ORO ESPAÑOL
}

a Rafael Morales, poeta y maestro

\section{Fuentes grecolatinas}

El mito de Hero y Leandro no se relaciona con ningún ciclo heroico concreto sino que, como tantas otras historias, vive independiente del resto.

Es posible localizar la leyenda en un entorno geográfico bien delimitado, el Helesponto, entre las ciudades de Sesto, en la ribera europea, y Abido, en la asiática, y cuya distancia ya había sido fijada por los antiguos, casi con total unanimidad, en 1295 metros. ${ }^{1}$

Museo $^{2}$ es el autor que nos relata la fábula con más profundidad y detalle, dedicándole al asunto un poema completo que consta de trescientos cuarenta y tres versos.

Leandro es un joven residente en Abido. Hero es una mujer muy bella de Sesto, sacerdotisa de Afrodita que se mantiene virgen, ignorando el matrimonio y viviendo en una torre con la única compañía de una sirvienta.

Hero y Leandro se conocen durante una fiesta que se celebra en honor de Venus y Adonis y a la que acuden los habitantes de los alrededores. Leandro queda prendado de la belleza de la joven, y es descrita por Museo como una segunda Venus que provoca la admiración de los muchachos. Leandro se enamora al instante de Hero y cuando llega la noche, se acerca a ella pero es rechazado de inmediato. Comienza la seducción amorosa por parte de Leandro que, para convencer a la muchacha, alude a la situación de Hero como sacerdotisa de Afrodita y utiliza como ejemplo a otro mito de la tradición clásica, el de Atalanta e Hipómenes. ${ }^{3}$ Las palabras de Leandro persuaden a Hero y en ella nace el

1 Museo, Hero et Léandro, Texte établi et traduit par Pierre Orsini, Paris, Societé d'edition les Belles Lettres, 1968, Introduction pág. VIII.

2 No se sabe a qué época exacta pertenece Museo pero se le presume contemporáneo de Nono de Panapolis que vivió en el siglo $V$ de nuestra era.

3 Atalanta, heroína del ciclo arcadio o beocio, según las distintas versiones, fue abandonada en el monte Partenio por no haber nacido varón y se crió adiestrada en el arte de la caza. Fue una obstinada virgen. Después de la cacería del jabalí de Calidón fue aceptada en la casa de su padre e instigada a elegir esposo. A todos los pretendientes los retaba a una carrera en la que si salía vencedora los mataría y si, por el contrario, era vencida, se casaría irremediablemente. Muchos eran los que habían sucumbido hasta que corrió al lado de Hipómenes. Éste fue dejando tres manzanas de oro, donadas por la diosa Venus, para que la invencible Atalanta se detuviera a cogerlas y perdiera tiempo en el certamen. Hipómenes se casó con Atalanta. Como se olvidó de agradecer a Venus su valiosa ayuda, Atalanta y él fueron convertidos en leones por obra de Cibeles. 
amor. Pero Hero no tiene el consentimiento de sus padres y tampoco los jóvenes se atreven a mostrar públicamente su relación. Por estos motivos, que no están desarollados en las versiones clásicas, propone Leandro que cada noche atravaserá el Helesponto a nado siempre que Hero encienda una lámpara que le guíe el camino a modo de estrella. Él expondrá su vida pero de este modo también evitará el escándalo.

Comienzan los encuentros amorosos durante algún tiempo. Leandro llega a Sesto por la noche, visita a Hero y regresa de nuevo a Abidos cuando raya el alba. Pero una noche de invierno se apaga la lámpara a causa de una tempestad y Leandro, al que el mar embravecido no le he hecho detenerse en su ya habitual viaje, invoca inútilmente a Venus, a Poseidón y al mismo Bóreas hasta que sucumbe ahogado. Hero, que ya ha presentido la muerte de su amante y que ha estado mirando el mar hasta el amanecer, distingue el cadáver de Leandro en la playa. La mujer, ante esta visión, se suicida tirándose de cabeza desde su torre.

Como ya se apuntó anteriormente, el poema de Museo es el que nos presenta la visión más completa del mito. Pero algunos poetas latinos nos muestran que ya conocían la leyenda. El primer testimonio escrito lo encontramos en Virgilio (Geórgicas III 258263). Es una alusión muy breve que nos presenta a Leandro nadando en la noche ciega aunque no hay una referencia directa a su nombre. 4

También tenemos alusiones muy breves en Ovidio (Amores II 30-31). Aquí el amante de Hero - innominado también- atraviesa a nado el mar. En Arte de Amar (II 249-250), Leandro pasa el Helesponto a nado para mostrarle (a Hero) sus sentimientos. En Tristes (III 40-41) e Ibis (verso 590), aparece también Leandro nadando. En las Heroidas (cartas XVIII y XIX) Ovidio nos amplía la información sobre el mito. En la carta XVIII, Leandro le escribe a Hero explicándole que hace ya varios días las aguas no le son propicias y que el mar está demasiado furioso. Pero si continúan los vientos adversos va a dirigirse a Sesto a pesar de las olas enemigas y aunque la audacia le cause la muerte. La carta XIX se la dirige Hero a Leandro que le pregunta impaciente por las causas que retrasan su viaje. Aparece aquí un personaje contradictorio que si bien se da cuenta de lo peligroso del trayecto, quiere que su amante atraviese el camino a pesar del mal tiempo y de la furia de las aguas. En las últimas líneas aparece el funesto presagio: Hero ha visto, en forma de sueño, a un delfín que llega muerto a la playa. Es el símbolo de Leandro sin vida suspendido en la superficie del mar.

Estacio (Theb V 542-547) también nos presenta a un Leandro cansado de nadar dentro de un mar alborotado y a una Hero que está esperándole. Marcial (Epigramas XXV y CLXXI) hace referencia a Leandro nadando en la noche. En Fulgencio (Mitolog. III, IV) también Leandro nada en la noche hasta que se muere a causa de la lámpara apagada por el viento. En Myth Vat I, 28 y II, 262 se alude a las dos ciudades separadas por el mar, Sesto y Abido, el enamoramiento de los jóvenes en la fiesta y el trayecto de Hero durante la noche dirigido por la lámpara que un día se apaga. Leandro llega muerto a la costa y Hero se suicida precipitándose en el mar.

4 El mito, gracias a la tradición oral, era ya conocido por los lectores y por esto no se hacía necesario nombrar a los personajes. 
En todas las fuentes grecolatinas tratadas en este trabajo hay una mención expresa al trayecto de Leandro desde Abido a Sesto. Este recorrido es real y posible. Lord Byron atravesó a nado el Helesponto en 1810.5

\section{El mito en el Siglo de Oro}

Es Garcilaso de la Vega quien introduce el tema de Hero y Leandro en la literatura española con el siguiente soneto:

Pasando el mar Leandro el animoso, en amoroso fuego todo ardiendo, esforzó el viento, y fuese embraveciendo el agua con un ímpetu furioso.

Vencido del trabajo presuroso, contrastar a las ondas no pudiendo, y más del bien que allí perdía muriendo, que de su propia vida congojoso,

como pudo esforzó su voz cansada, y a las ondas habló desta manera (-mas nunca fue su voz dellas oída-):

Ondas, pues no se escusa que yo muera, dejadme allá llegar, y a la tornada vuestro furor esecutá en mi vida. ${ }^{6}$

Garcilaso se inspiró directamente en el epigrama XXVb de Marcial:

Cum peteret dulces audax Leandro amores

est fessus tumidis iam premeretur aquis

sic miser instantes adfatus dicitur undas:

"Parcite dum propero, mergite cum redeo."7

Marcial, así como Garcilaso, no nos relata la historia completa sino que únicamente nos presenta a Leandro en el momento de pasar el Helesponto y que, vencido por el esfuerzo, se dirige en vano a las olas antes de morir.

Más prolijo fue Boscán en el tratamiento del mito, cuya temática le llega directamente de Garcilaso. Boscán le da a historia una dimensión nueva porque conoce muy bien la fábula a través de Museo aunque fuera Garcilaso el que le inspirara la composición.

5 Antonio Ruíz de Elvira, Mitología Clásica, Madrid, Gredos, 1988, 2² edición, pág. 491.

6 Garcilaso de la Vega, Obras Completas, Edic., introducción y notas de Antonio Gallego Morell, Barcelona, Planeta, 1983, p. 18.

7 Martial, Epigrammes, Lib. 24-26. Texte établi et traduit par H. J. Izaac, Paris, Las Belles Lettres, 1961, p. 10. 
Alrededor de 1537 compone Boscán un poema de 2560 versos endecasílabos blancos titulada La Historia de Hero y Leandro e inserta en el libro III de sus Obras Completas publicadas junto a las de Garcilaso.

Para la línea argumental del mito se basa en el poema de Museo, las cartas de las Heroidas de Ovidio y la fábula Ero e Leandro del italiano Bernardo Tasso.

En virtud a la extensión que dedica Boscán a la fábula, el poema está ampliado y enriquecido considerablemente y destaca algunos aspectos que no se encuentran en las fuentes antiguas pero que siguen los modelos erótico-corteses de los cancioneros del siglo XV y la tradición platónica del amor. Esta idealización del amor humano llegó al Renacimiento español procedente de Italia a través de $E l$ Cortesano de Castiglione (1528). Garcilaso le envió a Boscán un ejemplar desde Italia en 1533 y éste lo tradujo. La primera edición se imprimió en Barcelona en 1534. Las dos últimas partes de $E l$ Cortesano exponen esta filosofia del neoplatonismo. El amor debe ser virtuoso, sirve para despertar la razón y fortalecer el alma "atajando de tal manera los pasos a la sensualidad y cerrando así las puertas de los deseos". ${ }^{8}$ De esta manera, el único camino para amar es la unión exclusiva del alma por la contemplación de la belleza y de Dios. Esta concepción del amor está ejemplificada en la fábula mitológica de Boscán.

El poema comienza, siguiendo a Museo, con la invocación a la musa para que cante los amores de Hero y Leandro. Hero está presentada por Boscán como una dama del renacimiento:

"En Sesto una alta torre Hero tenía sobre la mar, en buen asiento puesta, dentro de la cual miraba, repartiendo sus horas en honestos ejercicios, para vivir sabrosa y cuerdamente. Este lugar sus padres se le dieron; pero no se le dieron por guardarla, con guardas, ni con premisas ni estrecheces.

Su vivir era libre, mas no sueto; su vivir era libre, mas no suelto; haciendo su querer cuanto quería, no hacía sino lo razonable, y en esta discordancia concordaba. Alegre estaba estando retraída; no buscaba solaz ni pasatiempos; antes los pasatiempos la buscaban.

8 B. Castiglioni, El cortesano, Traducción de Juan Boscán. Estudio preliminar de M. Menéndez Pelayo, Madrid, 1942, p. 383. 
Virgen y virginal su vivir era;

no andaba en competencias, ni asonadas,

Tan apartada de tener envidia estaba, que aun de quien se la tenía

se dolía entre sí y se lastimaba. [...]

Ella vivía, según hemos dicho,

recogida en su torre cuerdamente;

y envuelta en ejercicios virginales. ${ }^{9}$

Llega la fiesta en honor a Venus y Adonis, más extensa que en Museo, y Hero aparece resplandeciente y bella. Boscán aprovecha esta ocasión para realizar una loa a la hermosura, tópico literario renacentista, y exponer las muestras de admiración de los hombres que la contemplan. Sólo Leandro calla aturdido ante tanta belleza. Cuando se encuentran por primera vez: "allí era el salir a recibirse, / allí era el mezclarse de las almas;". ${ }^{10}$ Hasta este punto de la historia, Hero y Leandro representan el ideal platónico. El amor de Leandro es puro y Hero, cuyo género de vida es intachable, se mantiene virtuosa siguiendo los modelos de la época. Pero Boscán nos indica que "debajo de esta sanidad andaba / la pestilencia entrando por las venas". 11

Comienza el juego de la seducción. Incluso Leandro "atrevióse a tomar la mano de Hero" y la mujer, a diferencia de Museo que la retira irritada, no se molesta. Sólo cuando Leandro le intenta llevar a otro lugar ella le dice que es sierva de Venus y repite, con cierta violencia, las mismas razones que ya expusiera Museo. Leandro le responde:

"Mas el amor ningún peligro escucha, ni por dificultad suele atajarse.

Constreñido por él a tus pies me echo, ofreciéndote el alma por don grande para Dios, cuanto más para los hombres.

El cuerpo ha de ir tras ella en compañía; súfrela, pues es cuerpo de tu alma, que la mía es ya tuya puramente por ley de amor escrita en nuestras almas, y más te la doy y tú la tienes."12

Los demás argumentos también se inspiran en Museo, incluso utiliza el ejemplo de Atalanta y por todo esto la ley del amor acaba imponiéndose. Hero, sin embargo, y aunque está dispuesta a ceder, se lamenta de su comportamiento:

9 Garcilaso de la Vega y Juan Boscán, Obras Completas, Madrid, Crisol, 1961, pp. 430 y 431.

10 Ibídem, p. 437.

11 Ibídem, p. 440.

12 Ibídem, p. 449. 
"Sospecho que es algún pecado mío, o quizá la soberbia de mis padres, que siempre confiaron en mi tanto, que alguna vez, oyendo hablar de algunas que hubieron por amor hecho algún yerro, luego decían: ¡cuán lejos nuestra hija de verse en otro tanto, por más fuertes que fuesen los combates que le diesen! ¡Tristes de ellos, que así se han engañado; triste de mí, que así les he salido, tan al revés de cómo me esperaban."13

Y como Hero teme decepcionar a sus padres, sólo y por esta razón, a diferencia de las fuentes que hacen alusión a la extranjería de Leandro y al compromiso de virginidad por parte de las sacerdotisas de Venus, la relación no puede ser pública. Y así acuerdan el primer encuentro que se realiza como ya está atestiguado en la tradición mitográfica.

Boscán introduce algunas novedades más en su poema: el regreso de Leandro en su navío, con buen tiempo y mar seguro, y el cambio en su comportamiento, amante ahora de la soledad y sólo preocupado por ver a lo lejos la señal acordada que no llega.

Para explicar la tardanza de Hero, Boscán nos introduce una historia ajena a la que nos ocupa: la fábula de Aristeo y en la que se detiene minuciosamente, casi ochocientos versos. ${ }^{14}$ Dice el autor que Proteo, al que se le atribuye el don de la adivinación, congrega a la gente para revelar el oráculo. Se detiene especialmente en Hero, que ha acudido con sus padres al suceso, y le anuncia su porvenir.

Después de diez eternos y desesperados días, Leandro divida la lumbre en la ventana. Se ata la ropa a la cabeza y pide a las aguas que se amansen. Durante el tiempo que dura el recorrido de Leandro, y siguiendo esta vez a Ovidio, expresa Boscán los sentimientos contradictorios de Hero: por un lado se siente culpable por los padecimientos de Leandro y por el otro quiere que llegue pronto y - esto es novedad-se preocupa mirando a todas partes temerosa de que alguien descubra su falta.

Leandro llega a la orilla del mar, consuman sus amores y al amanecer, como ya conocemos, se marcha de nuevo. Hero se queda en la torre como "la hija quedó del rey de Creta / al tiempo que Teseo la dejó sola, / olvidada en la isla entre alimañas".15

13 Ibídem, pp. 454 y 455.

14 Virgilio cuenta en Las Geórgicas (IV, 317 ss.) la fábula: Eurídice, mientras huía perseguida por Aristeo, hijo de Apolo y la ninfa Cirene, fue mordida por una serpiente y murió. Los dioses, encolerizados, lo castigaron enviando una epidemis a sus abejas. Éste pidió ayuda a su madre. Cirene le dijo que sólo Proteo podría explicarle los motivos de su desgracia. El dios marino le dijo el porqué de su castigo y le dio consejos para obtener nuevos enjambres.

15 Juan Boscán, obra citada, p. 506. Se refiere a Ariadna, hija de Pasifae y Minos. Se enamoró de Teseo que había llegado a Creta para luchar con el Minotauro. Ariadna lo ayudó a encontrar el camino del laberinto con un ovillo que le indicó el camino de regreso. Huyó con Teseo pero éste la abandonó en la isla de Naxos aprovechando que estaba dormida. 
Comienza el invierno - aquí Boscán no indica si se producen más citas- y Leandro no puede nadar a causa del mal tiempo. Otra vez, siguiendo a Ovidio, se mezclan los sentimientos de Hero que quiere poner la lumbre en la ventana a pesar de que ya se ha apagado varias veces a causa del viento, aviso ya de la desgracia presentada en Museo, y nos narra la impaciencia de Leandro mirando continuamente el mar, alternando la esperanza con la desesperación. Por fin Leandro comienza su trayectoria después de ver la lámpara encendida y:
"Súbitamente en esto, las tres parcas
sus cuchillos tomaron en las manos,
apercibidas, aguardando el punto
para cortar los tratos y las vidas
delos tristes amantes mal logrados". 16

Después de invocar a Venus y a Neptuno, el mar lo absorbe en el preciso instante en que se apaga la lumbre. Hero se deja caer desde la ventana cuando ya ha visto el cuerpo de Leandro en la orilla del mar. Y Boscán finaliza la historia: "así se fueron juntas las dos almas / a los Campos Elíseos para siempre". 17

Sabemos que Boscán realizó su composición después de la muerte de Garcilaso. Es inevitable que algunos de los versos de esta fábula nos recuerden a los del soneto. Boscán nos presenta un Leandro "de fuego ardiente abrasándolo dentro de su alma" que "con animoso acuerdo decide enfrentarse con las olas". Ante las dificultades del trayecto, que ya ha emprendido, repite las mismas palabras que emite Leandro en el soneto garcilasiano para calmar a las aguas, recuerdo del epigrama de Marcial al que ya aludimos pero que seguramente'Boscán tomó directamente de su contemporáneo. Pero mientras que para Garcilaso son los últimos momentos de Leandro - las olas no han escuchado sus súplicas y finalmente parece- Boscán introduce una variante porque sabemos que Leandro "a la orilla llegó".

Sin embargo el mérito de Garcilaso fue el de introducir el tema en la literatura de Siglo de Oro. Su soneto, que estaba impreso en pliego suelto desde 1536, tuvo muchos imitadores y Hero y Leandro se convirtieron en un recurso temático que fue enriqueciéndose y moldeándose con las diversas versiones de otros poetas.

Sá de Miranda es uno de los primeros autores que engrosa la lista de los que imitaron a Garcilado en el tratamiento del tema. En su soneto "A la muerte de Leandro" encontramos muchos paralelismos con aquel autor aunque hay algunas novedades: Sá de Miranda localiza espacialmente la acción entre Sesto y Abido y en el segundo terceto Leandro desafia a las olas diciéndoles que no van a impedir su llegada aunque sea muerto.

Más fiel a la fuente garcilasiana es Gutierre de Cetina que compuso un soneto en la misma línea y que no aporta novedades en cuanto al tema pero va depurando el estilo poético.

\footnotetext{
16 Boscán, obra cit., p. 516.

17 Boscán, obra cit., p. 522.
} 
Juan de Valdés y Meléndez compuso otro soneto dedicado al tema. La única novedad con respecto a Garcilaso es que Valdés refleja su situación personal. En el último terceto se dirige a Leandro por el que siente envidia ya que al menos el personaje ha disfrutado del amor en tres o cuatro ocasiones antes de perecer en las aguas.

Hipólita de Narváez compone otro soneto y que aquí reproduzco:

Rompe Leandro, con gallardo intento,

El mar confuso, que soberbio brama,

Y el cielo, entre relámpagos derrama

Espesa lluvia con furor violento.

Sopla con fuerza el animoso viento;

¡Triste de aquel que es desdichado y ama!

Al fin al agua ríndese la llama,

Y a la inclemente furia es sufrimiento.

Mas joh infelice amante! pues al puerto

llegaste, deseado por tí tanto,

Aunque con cuerpo muerto y gloria incierta.

$Y$ desdichada yo, que en mar incierto

Muriendo entre las aguas de mi llanto

Aun no espero tal bien después de muerta. ${ }^{18}$

Como Juan de Valdés muestra su situación personal y la compara con la de Leandro aunque ella es todavía mucho más desventurada. El mito, pues, le sirve de excusa para reflejar sus propios sentimientos.

El soneto XXII de Juan de Arguijo titulado "Leandro" comienza también con la natación del amante y no nos aporta novedades temáticas.

El soneto 195 de Camões, compuesto en 1616, también pertenece a la serie de aquellos que imitaron a Garcilaso. Ya que Leandro se da cuenta de que va a morir, se encomienda al mar y le pide que al menos salve a Hero pues teme que la mujer lo vea muerto y se suicide.

Francisco de Aldana fue más lejos porque glosó el soneto de Garcilaso en doce octavas reales. Faltan las glosas a los dos versos centrales del segundo cuarteto. También se realizaron otras composiciones semejantes como ya muy bien indica José Lara Garrido en la edición de las poesías completas de Aldana. ${ }^{19}$

La primera octava del poema de Aldana nos presenta el lugar de la desgracia, un estrecho situado entre Asia y Europa en donde el viento sopla con violencia, y nombra a los

18 Poetas líricos de los siglos XVI XVII, Colección ordenada por D. Adolgo de Castro, Madrid, B.A.E., 1951.

19 José Lara Garrido comenta algunas de estas composiciones: la del cartapacio salmantino de Pedro de Lemos, en catorce octavas reales; la del cartapacio de Francisco Morán de la estrella y que glosa sólo siete versos; la del cancionero de Borges, en siete octavas y la composición anónima inserta en Flores de baria poesía.

Francisco de Aldana, Poesias castellanas completas, Ed. de José Lara Garrido, Madrid, Cátedra, 1985, pp. 123 y 124. 
dos implicados en la historia, Hero, mirando triste el mar y Leandro "solo entre las ondas".

Discurre el poema como ya conocemos con la novedad de que Aldana, a diferencia del resto de las composicones que relatan la historia de manera objetiva, se introduce en el poema e impreca directamente a las Parcas para que salven a Leandro: " $\mathrm{OOh}$ Parcas! ¿cómo sois tan mal miradas / en no aguardarle, a la tornada, muerte? (versos 29-30). Y en la siguiente octava:

"Déjale, joh Parca!, ver dentro en los brazos

de su querida y de su amada Hero, concédeles que den sendos abrazos en remembranza de su amor primero; aplaca el mar que en tantos embarazos por evitar, se puso, un gozo entero; ¿Y no le ves sin fuerza y sin reposo, vencido del trabajo presuroso?"20

Hero desde la torre está esperando a Leandro y, a su vez, tembién le habla a las ondas y le pide a Dios socorro para su amante, lo que supone un anacronismo con respecto a las fuentes originales. El cielo no escucha las súplicas y al final Leandro se muere. Aldana finaliza aquí la composición y no hace alusiones al suicidio de Hero.

Diego Hurtado de Mendoza fue el primer poeta introductor de la fábula mitológica en España, género que alcanzaría su máximo esplendor en el siglo XVIII. Este autor había pasado gran parte de su vida en Italia y se inscribió con rapidez en los nuevos versos y modelos procedentes de ese país. En sus composiciones utiliza frecuentes alusiones míticas y compuso la primera obra de temática ovidiana basada en Las Metamorfosis que fue el libro más traducido y consultado de todo el Siglo de Oro.

La composición de Hurtado de Mendoza, Fábula de Adonis, Hipómenes y Atalanta, apareció por primera vez en 1553 en la edición que hiciera Alonso de Ulloa de las obras de Boscán y Garcilaso.

El poema está escrito en octavas reales y sigue muy de cerca al texto de Ovidio aunque está ampliada la versión con otras alusiones mitológicas y nuevas circunstancias personales. El autor dedica dos octavas al recuerdo de Hero y Leandro:

" $¿$ Quién dio fuerzas al joven que, de hecho,

le enciende amor y le resuelve en fuego,

en noche escura el tempestuoso estrecho

atravesar con lluvia y tiempo ciego,

cortar las bravas olas con el pecho?

Truena y ábrese el cielo y el mar luego

rompe las altas peñas resonando,

${ }^{20}$ Las dos citas corresponeden a las Poesias Castellanas completas de Francisco de Aldana. Obra cit., p. 125. 
más él, con su furor, pasa nadando.

No le tienen turbados elementos,

no los padres con lágrimas y llanto,

el Mar Negro sacado de cimientos

no le aparta el deseo o pone espanto,

no la virgen que en ansias y tormentos

suspensa pasará aquel entretanto

$\mathrm{y}$ al fin morirá muerte lastimera

sobre el cuerpo tendido en la ribera."21

Estas palabras salen por boca de Venus cuando está intentando disuadir a Adonis de su peligriosa afición por la caza y le relata, a modo de ejemplo, la fábula de Hipómenes y Atalanta, tema principal del poema de Mendoza.

La composición de Hurtado de Mendoza es anterior a la de Aldana pero su fuente no es Garcilaso, como ha venido siendo habitual hasta ahora, sino que - para el mito de Hero y Leandro- se inspira directamente en los versos que Virgilio dedica al asunto:

"Quid iuuenis, magnum ciu versat in ossibus ignem

durus amor? Nempe abruptis turbata procellis

nocte natat caeca serus freta; quem super ingens

porta bonat caeli, et scopulis inlisa reclamant

aequora; nec miseri possunt reuocare parentes

nec moritura super crudeli funere virgo." 22

En el Cancionero General, recopilado por Hernando del Castillo y cuya primera edición se imprimió en 1511, hay un soneto anónimo que recoge el punto de vista de Hero a al que podemos considerar como compañero del Garcilaso:

Hero del alta torre do mirava

a su Leandro que en el mar venía

helósele la sangre que tenía

murióse quando vio que muerto estava.

Con lágrimas el mar acrecentava

el ayre con sospiros encendía

estremos eran grandes los que hazía

palabras eran tales las que hablava.

O mal logrado esposo o dulce amigo

esperame no partas que ya muero

de un golpe dio la muerte dos heridas

21 Diego Hurtado de Mendoza, Poesía completa; Edición, introducción y notas de José Ignacio Díez Fernández, Madrid, Planeta, 1989, p. 121.

22 Virgile, Geórgiques. Texte établi et traduit par E. de Saint-Denis, Paris, Las Belles Lettres, 1963, p. 47. 
recibeme mi bien alla contigo

ado murio Leandro muera Hero

parezcanse las muertes a las vidas. ${ }^{23}$

Este soneto también fue glosado en siete octavas reales con la particularidad de que cada estrofa incorpora dos endecasílabos del soneto. La composición comienza: La ora que Leandro pretendía... y también está recogida en el Cancionero General de Hernando del Castillo. Su autor es anónimo.

La glosa recoge el sufrimiento de Leandro mientras está en el agua y el de Hero que mira el suceso desde la torre. A partir de la tercera octava, y como Leandro ha sido ya arrastrado por el agua hasta la orilla, sólo se refiere a la mujer que decide suicidarse.

El Cancionero General de Hernando de Castillo recoge casi en su totalidad poemas que exponen la herencia del trovadorismo medieval. En el Renacimiento convivieron las formas italianas, cuyos introductores fueron Boscán y Garcilaso, y el verso castellano tradicional. Prueba de este apego a la tradición española fueron las nueve ediciones que se imprimieron del Cancionero General desde 1511 hasta 1573 y el gran auge que en el siglo XVI tuvieron los cancioneros y romances.

En el cancionero Flor de Enamorados (Barcelona, 1562), recogido por Timoneda, se encuentran dos romances que son un recuerdo del mito de Hero y Leandro. El primero comienza con la natación de Leandro por el Helesponto, el proceso de la tempestad y su muerte mientras pronuncia el nombre de Hero. En el segundo romance, que es compañero del anterior, Hero está esperando a su amante que no llega, lo ve muerto en la playa y se tira por la ventana. Al igual que en Boscán:

“A Leandro acompañando

La hermosa Hero moría:

En los Campos Elíseos

A Hero y Leandro en compañia

Sepultaron juntamente

Con tristeza y agonía."24

También Hernando de Acuña compuso un soneto en el que Hero está mirando hacia el mar desde su torre y que cuando divisa el cuerpo de Leandro en la ribera se suicida.

De Fernando de Herrera es un romance que también, y como ya va siendo habitual en este tipo de composiciones, indica la natación de Leandro. Esta vez la fuente directa de Herrera no es ninguno de los poemas que los escritores españoles habían realizado hasta el momento sino que toma directamente, como el propio Herrera indica, el epigrama XXVb de Marcial: Cum peteret dulces audax Leandro amores, utilizado anteriormente por Garcilaso.

La letrilla LXXIV atribuída a Góngora comienza con una alusión del mito:

23 Romancero General o colección de romances castellanos anteiores al siglo XVIII; Recogidos, ordenados y clasificados por Agustín Durán, Tomo I, Madrid, B.A.E., 1945.

24 Ibídem, p. 313. 
Échose Leandro al mar,

Ero en esto se desvela,

hecha norte y centinela

por amar;

Mas viendo muerto llegar

al que en sus brazos espera,

se arrojó como si fuera

el remedio a su dolor, por el amor. ${ }^{25}$

Continúa con la fábula de Paris y Elena, Príamo y Tisbe y algunas más y termina diciendo:

nadie se debe espantar

en ver que de amores muero,

pues yo no soy el primero

que muere deste dolor,

por el amor. ${ }^{26}$

Los mitos son utilizados para ejemplificar, a través de los desgraciados amantes de la antigüedad, su propia circunstancia personal como ya antes hicieran otros autores.

De Góngora también es un romance burlesco que comienza: Aunque entiendo poco griego, compuesto en 1610. La composición de fábulas mitológicas burlescas es un fenómeno típico del culteranismo. Los autores que se adscriben a esta corriente desmitificadora se alejan de la tradición literaria del Renacimiento y se disponen a ridiculizar a los personajes de la mitología clásica. "Quien primero las compone en España es Luis de Góngora, y es curioso que sea precisamente el autor de una obra, la más eminente del género, quien logra su caricatura. Porque, en realidad, el género burlesco de poemas mitológicos no es sino la autocrítica de una escuela, toda una manera retórica reaccionando sobre sí misma para la burla y para la sátira."27

Góngora trata el tema de Hero y Leandro en dos composiciones que esta actitud crítica ante las historias amorosas de la mitología clásica. Los temas habían sido contemplados de manera formal en el siglo XVI y parece que este tipo de versiones burlescas estaban apuntando ya una cierta decadencia en cuanto a la recreación de estos temas. Es también significativo el hecho de que Góngora hubiera escogido el romance como fórmula métrica para burlarse de sus personajes. La composición comienza haciendo referencia a la fuente utilizada, Museo, aunque vamos a ver cómo se ha desviado de este autor.

Góngora se sirve de anacronismos para situarnos el tiempo en el que transcurre la fábula. El padre de Hero es un hidalgo, alcalde de Sesto y su madre una griega "con más partos y postpartos / que una vaca". A su vez Leandro es el hijo de un escudero muy pobre de Abido. Se conocen los dos amantes y comienza la seducción:

\footnotetext{
25 Góngora, Letrillas; Edición, introducción y notas de Robert Jammes, Madrid, Castalia, 1980, p. 219.

26 Ibídem, p. 221.

27 José $\mathrm{M}^{2}$ de Cossío, Fábulas mitológicas en España, Madrid, Espasa-Calpe, 1952, p. 517.
} 
"Pióla cual gorrión

cacareóla cual gallo,

arrullóla cual palomo,

Hízola ruedas cual pavo.

Ella del guante al descuido

desenvainando una mano,

le aseguró y de dió un bello

cristalino cintarazo." 28

Los amantes acuerdan la cita con la señal convenida y una noche Leandro cruza el mar. El romance contiene dos digresiones: una crítica a los versos de Boscán y otra a los títulos nobiliarios:

"Los títulos me perdonen, y el dibujo prosigamos, que si no los tuvo Grecia, los pidió a España prestados."29

Este romance, que termina cundo Leandro se arroja a las aguas, tiene su continuidad en otro romance del mismo autor que comienza: Arrojóse el mancebito... Cronológicamente fue compuesto primero pero prosigue la historia de los dos amantes. Se inicia con la natación de Leandro y continúa con el resto de la fábula hasta el final.

Las alusiones cultas son mínimas y hay un cambio radical en la resolución del tema. Leandro se arroja "al charco de los atunes" cuando comienza la tempestad y continúa con el mismo tono irónico el resto del romance.

El mancebo ruega a Cupido y Venus que lo amparen en la empresa aunque Góngora justifica sorpresivamente el olvido divino diciendo:

"Pero Amor, como llovía

y estaba en cueros, no acude,

ni Venus, porque con Marte

está cenando unas ubres." 30

Leandro muere por fin y Hero, que no ha dejado de maldecir y acusar a todas las estrellas del cielo, ve el cadáver desde su torre. Con un punzón, y antes de arrojarse al mar, graba ella misma el epitafio de su tumba:

"Hero somos y Leandro

no menos necios que ilustres, en amores y firmezas

al mundo ejemplo comunes.

28 Góngora, Romances; Edición de Antonio Carreño. Madrid, Cátedra, 1982, p. 342.

29 Ibídem, p. 343.

30 Ibídem, p. 207. 
El amor como dos huevos, quebrantó nuestras saludes;

él fue pasado por agua, yo estrellada mi fin tuve.

Rogamos a nuestros padres que no se pongan capuces, sino, pues un fin tuvimos, que una tierra nos sepulte." 31

Este sistema desmitificador es utilizado por otros autores después de Góngora. Mateo Vázquez de Leca compone un soneto que sigue reflejando este carácter burlesco que ya comenzara su antecesor y que aquí transcribo:

¡Cuerpo de Dios! Leandro enternecido

¿Cuánto mejor te fuera haber pasado

En barcos de la vez el mar salado,

Que no pasar a nado desde Abido!

¿No te fuera mejor haber vivido,

Yá pies enjutos tu mujer gozado,

$Y$ no llegar a Sesto resfriado

En la primera noche de marido?

No son tan necios otros amadores,

Que pasan a Triana de Sevilla

Todas las noches en banquetes nuevos.

Buen aliño tuvieron tus amores:

Tú pasado por agua, Hero en tortilla,

$Y$ cenóse el diablo el par de huevos. ${ }^{32}$

Si con Góngora los dioses antiguos mantenían su categoría de tales, a pesar de la ridiculización de que son objeto los héroes de la mitología clásica, con Quevedo la burla y el sarcasmo llega a límites insospechados. El romance en versos cortos "Hero y Leandro en paños menores" nos indica ya desde su título el carácter que este autor va a darle a su fábula.

Hero es una moza de una venta llamada La Torre - aquí la transformación de la torre en la que vivía Hero por el nombre de una posada - que se dedica a la prostitución y cuyos clientes principales son los marinos que se paran allí a descansar. Leandro es uno de estos hombres que es recibido por Hero cada noche. Quevedo satiriza en extremo la relación sexual de la prostituta y el navegante. A través de alusiones a diversos refranes y metáforas despectivas, interrogaciones retóricas y lenguaje vulgar, el autor acelera el ritmo de romance, mucho más narrativo en Góngora, y nos ofrece una versión escéptica para llegar a la máxima deformación en el tratamiento de los modelos antiguos. Quevedo se sirve de algunas imágenes conocidas —el huevo pasado por agua para designar la

\footnotetext{
31 Ibídem, pp. 208-209.

32 Pedro de Espinosa, Flores de poetas ilustres, Valladolid, 1605.
} 
natación de Leandro y una Hero estrellada en el epitafio final- utilizadas anteriormente, como ya hemos dicho, por Mateo Vázquez de Leca y Góngora en su versión 1610.

Se debe considerar la absoluta decadencia en el tratamiento del género que alcanzaría su máximo apogeo en la primera mitad del siglo XVIII con Francisco Nieto y Molina, entre otros.

De la historia de Hero y Leandro también tiene Quevedo una versión seria que nos cuenta la historia amorosa de los dos personajes. La única novedad con respecto a las fuentes grecolatinas y a la dimensión que le dieron el resto de los poetas hasta aquí mencionados, es el suicidio de Hero sin llegar a conocer la muerte de su amante.

Gabriel Bocángel y Unzueta es el autor del poema heroico "Fábula de Hero y Leandro" compuesto en ciento cuatro octavas reales. Está dedicado a Jaúregui, poeta con el que tuvo puntos de contacto personales y literarios.

Siguiendo a Museo y a Boscán comienza el poema con la invocación a las musas aunque él nombra sólo a Melpómene, la musa de la tragedia. Le pide que le cuente la historia del joven y la virgen e invoca al Betis, río de Sevilla, en lo que supone un acercamiento espacial a la tierra española. Todavía antes de comenzar su fábula hay una loa a Jaúregui y nos sitúa de inmediato la historia entre Europa y Asia sin nombrar las ciudades respectivas que habitan los amantes. Se describe prolijamente la belleza de Hero, la discreción de Leandro y el templo donde tiene lugar la declaración de amor. En la manifestación de los sentimientos de Leandro y los argumentos para convencer a la muchacha excepto en la ejemplificación del mito de Atalanta e Hipómenes al que no se dedicasigue a las fuentes citadas así como la determinación de encontrarse en secreto, detalle aprovechado por Bocángel para moralizar la historia:

" $\mathrm{OOh}$ acuerdo de los hombres imprudente!

Tus aciertos son fábulas del hado.

¿Qué lejos de sus juicios, ay, qué lejos, nos labramos rü̈nas y consejos!" 33

Se ven los amantes - Bocángel dice que fueron mil, en una evidente exageraciónhasta que una de las noches comienza una tempestad que termina con la vida de Leandro y con el suicidio de Hero que se abalanza sobre una almena. Este trágico final es para Bocángel el castigo final de unos personajes que no se han comportado según sus esquemas morales. La última octava del poema así nos lo indica:

"Sesto después, en funeral oficio, himnos mil sobre el féretro derrama, $y$ hace que vivan en su precipicio los amantes la vida de la fama.

${ }^{33}$ Gabriel Bocángel, Antología poética; Ed. de Luis Alberto de Cuenca, Madrid, Editora Nacional; 1982, p. 152. 

Allí murió Cupido, que ya el vicio
le sustituye, y su noticia infama, donde tendrán en merecido templo, lástima el libre y el amante ejemplo." 34

De Francisco de Trillo y Figueroa es otro poema heroico en forma de romance que comienza con el lanzamiento de Leandro al mar. Este autor no nos expone nada nuevo en cuanto al tema pero invoca continuamente a Leandro para que se detenga y evite el desastre. También hay una moralización en algunos versos "Ero, venenoso halago / y lascivo desconsuelo" aunque no es tan evidente como la de Bocángel y en contraposición a aquél no se implica en el final trágico de la fábula.

Francisco Rodrígues Lobo, poeta portugués que escribe en lengua castellana, compone dos romances que relatan la fábula. El primero, titulado "Romance a la muerte de Leandro" comienza cuando ya éste está luchando contra las aguas. Le pide a las olas que se tranquilicen - en un recuerdo al soneto de Garcilaso y todos sus seguidores- y se dirige a Hero, que no le escucha, diciéndole las dificultades que tiene de llegar a la orilla. En el segundo titulado "Otro, al mismo", ya tenemos el cuerpo de Leandro muerto en la playa. En este romance sí que hay también una moralización de la desgracia, "que Amor hizo atrevido, / que hace ciegos los amantes / e invisibles los peligros". ${ }^{35}$

Hero entiende que la muerte de su amante ha sido un castigo y decide suicidarse. Dos versos de Rodrígues Lobo nos recuerdan los poemas que ya encontráramos en el Cancionero de Hernando del Castillo: "parézcanse ansí las muertes / de dos vidas que una han sido". 36

Hasta aquí el recorrido que los poetas del Siglo de Oro hicieron sobre el tema de Hero y Leandro. Originado en el folklore popular de los antiguos y plasmado posteriormente por los autores clásicos, esta fábula ha dado tema y motivo a diversas creaciones literarias del siglo XVI y XVII. El mito regresa al Renacimiento con gran intensidad y en el barroco se acumulan todos los procedimientos estilísticos para lograr una mayor expresividad, se moraliza e incluso es utilizado para constituirse como género propio con las fábulas mitológicas. Todo ello nos demuestra que el entusiasmo por la Antigüedad Clásica continúa latente permitiendo plantear nuevas exigencias y caminos expresivos.

\footnotetext{
34 Ibídem, p. 163.

35 Francisco Rodrígues Lobo, Primera e segunda parte de dos romances, Lisboa, 1654, p. 106.

36 Ibídem, p. 107.
} 
Musée, Héro et Léandre. Texte établi et traduit par Pierre Orsini, Paris, Les Belles Lettres, 1968.

Virgile, Géorgiques. Texte établi et traduit par E. Saint-Denis, Paris, Les Belles Lettres, 1963.

Ovide, Les amours. Texte établi et traduction par Henri Bornecque, Paris, Les Belles Lettres, 1961.

L'art d'aimer. Texte établi et traduction par Henri Bornecque, Paris, Les Belles Lettres, 1960.

Tristes. Texte établi et traduction par Jacques André, Paris, Les Belles Lettres, 1968.

Heroïdes. Texte établi et traduction par Henri Bornecque, Paris, Les Belles Lettres, 1961.

Estacio, La Tebaida. Traducida en verso castellano por el Lincenciado Juan de Arjona, Madrid, Librería de los Sucesores de Hernando, 1915.

Martial, Epigrammes. Texte établi et traduit par H. J. Izaac, Paris, Les Belles Lettres, 1961, Tome I et II.

Fulgencio, Mytologiarium. Recensuit Rudolfus Helm. Lipsiae, in aedibus B. G. Teubneri, 1898.

Mythographi Vaticani. Tvrnhholti. Typographi Brepols, Editores Pontificii, 1987.

B. Castiglione, El Cortesano. Traducción de Juan Boscán, Estudio preliminar de M. Menéndez Pelayo, Madrid, 1942.

Garcilaso de la Vega, Obras completas. Edición, introducción y notas de Antonio Gallego Morell, Barcelona, Planeta, 1983.

Juan de Boscán y de la Vega, Garcilaso, Obras completas. Madrid, Crisol, 1961. Poetas líricos de los siglos XVI y XVII. Colección ordenada por D. Adolfo de Castro, Madrid, B.A.E., 1966, Volumen XLII.

Poetas líricos de los siglos XVI y XVII. Colección ordenada por D. Adolfo de Castro, Madrid, B.A.E., 1951, Volumen XXXII.

Luis de Camões, Obra completa. Rio de Janeiro, Companhia Aguilar Editora, 1963. Juan de Arguijo, Obra poética. Edición, introducción y notas de Stanko B. Uranich, Madrid, Clásicos Castalia, 1982.

Francisco de Aldana, Poesías castellanas completas. Edición de José Lara Garrido, Madrid, Cátedra, 1985.

Hernando del Castillo, Cancionero General. Reimpresión de 1537.

Romancero General o colección de romances castellanos anteriores al siglo XVIII.

Recogidos, ordenados y clasificados por Agustín Durán. Madrid, B.A.E., 1945.

Diego Hurtado de Mendoza, Poesía completa. Edición, introducción y notas de José Ignacio Díez Fernández, Madrid, Planeta, 1989. 
Francisco de Sá de Miranda, Obras completas. Texto fixado, notas e prefácio pero prof.

M. Rodrígues Lapa, Volume I, Lisboa, Livraria Sá de Costa, 1937.

José María de Cossío, Fábulas mitológicas en España. Madrid, Espasa-Calpe, 1952.

Hernando de Acuña, Varias poesías de . Edición de Elena Catena de Vindel, Madrid, 1954.

Francisco de Herrera, Obra poética. Edición crítica de José Manuel Blecua, Madrid, 1975.

Luis de Góngora, Letrillas. Edición, introducción y notas de Robert James, Madrid, Clásicos Castalia, 1980.

Francisco de Quevedo, Obras completas. Poesía original, Vol. I. Edición, introducción, notas y bibliografía de José $\mathrm{M}^{\mathrm{a}}$ Blecua, Barcelona, Planeta, 1963.

Pedro de Espinosa, Flores de poetas ilustres. Valladolid, 1605.

Gabriel Bocángel, Antología poética. Edición de Luis Alberto de Cuenca, Madrid, Editora Nacional, 1982.

Francisco Rodrígues Lobo, Primera e segunda parte dos romances. Lisboa, 1654. Antonio Ruiz de Elvira, Mitología clásica. Madrid, Gredos, 1988, $2^{\mathrm{a}}$ edición.

\section{Povzetek}

\section{MIT O HERO IN LEANDRU: NEKAJ GRŠKO LATINSKIH VIROV IN PRISOTNOST MITA V ŠPANSKI ZLATI DOBI}

Namen pričujočega prispevka je prikazati prisotnost mita o Hero in Leandru $v$ španski zlati dobi. Avtorica se poglobi v študijo grško latinskih virov, razmišlja, kako se mit zrcali $v$ delih španskih piscev, kako so ga obravnavali pesniki tega obdobja in kako je mit služil literaturi od Garcilasa in Boscána do Góngore in Queveda. 